\title{
CÂMBIO: Um olhar etnográfico sobre a saúde e as diversas formas de vivenciar o esporte adaptado na velhice
}

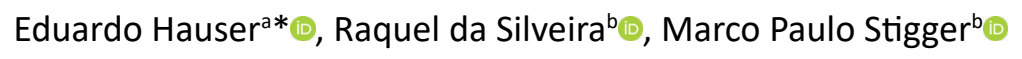

Palavras Chave:

Estilo de vida;

Esportes;

Envelhecimento;

Saúde.

Keywords:

Life style;

Sports;

Aging;

Health.

\begin{abstract}
RESUMO
O esporte adaptado para idosos tem por objetivo reduzir a intensidade do jogo e incluir aqueles que não se consideram aptos a jogar. O objetivo desse estudo é compreender a prática do Câmbio vivenciada por idosos e suas possíveis relações com a saúde, no seu entendimento mais amplo. Durante a pesquisa etnográfica, foram investigados dois grupos de câmbio da cidade de Porto Alegre/RS. Foram realizadas 23 observações e oito entrevistas semiestruturadas. Em um mesmo momento, a prática esportiva pode acarretar em benefícios para uma dimensão relacionada à saúde enquanto que pode atenuar 'riscos' em outros aspectos. Espera-se que esse debate possa auxiliar professores e organizadores de eventos a refletirem sobre suas práticas, relacionado os aspectos da saúde e do esporte na velhice.
\end{abstract}

\begin{abstract}
Aged people sports aim to reduce the intensity of the game and include those who do not consider themselves fit to play. The aim of this study is to understand the practice of "Câmbio" experienced by the elderly and their relationships with health, in its broader understanding. During the ethnographic research, two exchange groups from the city of Porto Alegre / RS were investigated. Twenty-three observations and eight semi-structured interviews were conducted. At the same time, sports can bring benefits to a health-related dimension while mitigating 'risks' in other respects. It is hoped that this debate can help teachers and event planners to reflect on their practices related to health and sports aspects in old age.
\end{abstract}

\section{RESUMEN}

El objetivo de los deportes adaptados para personas mayores es reducir la intensidad del juego e incluir a aquellos que no se consideran aptos para jugar. El objetivo de este estudio es comprender la práctica de "câmbio" que experimentan los ancianos y sus posibles relaciones con la salud, en su más amplio conocimiento. En estudio etnográfico, se investigaron los grupos de cambio de la ciudad de Porto Alegre / RS. Se realizaron 23 observaciones y 8 entrevistas semiestructuradas. Al mismo tiempo, el deporte puede aportar beneficios a una dimensión relacionada con la salud al tiempo que mitiga los "riesgos" en otros aspectos. Se espera que este debate pueda ayudar a los maestros y organizadores de eventos a reflexionar sobre sus prácticas con los aspectos de salud y deportes en la vejez.

\footnotetext{
a Universidade Federal de Santa Catarina (UFSC), Programa de Pós-graduação em Educação Física, Florianópolis, SC, Brasil.

b Universidade Federal do Rio Grande do Sul (UFRGS). Departamento de Educação Física, Fisioterapia e Dança (ESEFID/UFRGS), Porto Alegre, RS, Brasil.
}

* Autor correspondente: Eduardo Hauser

E-mail: Ehauser07@gmail.com

Recebido em 15 de Outubro de 2019; Aceito em 24 de Janeiro de 2020. 


\section{INTRODUÇÃO}

A população mundial se encontra em franco processo de envelhecimento (WHO, 2015), sendo que a nível de Brasil, dados mostram que a população idosa passou de $8,5 \%$ no Censo 2000 para $10,8 \%$ da população no Censo de 2010 (IBGE, 2010). Dessa forma, cresce a atenção por parte de pesquisadores e de algumas instituições públicas para que os idosos vivenciem a velhice com mais qualidade e saúde através de ações cotidianas.

Para a promoção da saúde na velhice e problematizar o debate acerca desse tema, é importante relembrar que o conceito de saúde, segundo a Organização Mundial da Saúde, é o estado de completo bem-estar físico, mental e social (WHO, 1978). Na mesma direção, Deponti e Acosta (2010) compreendem que para um envelhecimento saudável é necessário um equilíbrio ou uma combinação de múltiplos fatores, sejam de ordem biológica, psicológica ou social. Uma das estratégias para a promoção da saúde em idosos que agrega esses múltiplos fatores é a prática de exercícios físicos (WHO, 2010). Sabe-se que o exercício físico traz diversos benefícios para a saúde dos idosos (Warburton et al., 2016; Wong et al., 2018), porém ainda não há uma resposta sobre qual a melhor forma de exercício para essa população (Labra et al., 2015), visto que pessoas de idade avançada apresentam necessidades multidisciplinares.

Dentre as opções de atividades físicas para os idosos, o esporte pode ser uma opção na velhice, podendo ser vivenciado de diversas formas. Seja de maneira mais lúdica, com uma conotação de 'brincadeira' (Famose, 1999) e 'voltado para si' (Elias e Dunning, 1992), se aproximando da lógica do 'esporte-lazer' (Silveira, 2008) ou pode ser vivenciado de uma maneira pautada pelo resultado, sob a lógica do 'trabalho' (Famose, 1999), 'voltado para os outros' (Elias e Dunnig, 1992) se aproximando da lógica do 'esporte-rendimento' (Silveira, 2008).

Para além do esporte ser voltado ou para a lógica do esporte-lazer ou para o esporte-rendimento, é importante atentar que "uma mesma prática esportiva possa ser realizada por diferentes indivíduos e grupos, que podem dela se apropriar de várias formas, atribuindo-lhes significados diversos" (Stigger, 2005, p. 76). Dessa forma, estudos etnográficos realizados tanto em população adulta (Silveira, 2008; Pacheco; Stigger, 2016) quanto idosa (Hauser et al., 2015) apontam que um mesmo grupo praticante de determinada modalidade esportiva pode apresentar significados distintos para essa prática, tanto significados voltados para o esporte-lazer como significados que se aproximam com a lógica do esporte-rendimento, ou ainda outros sentidos vinculados a diferentes esferas da vida, como por exemplo, as questões de gênero e sexualidade.

Em relação às instituições públicas é possível identificar algumas ações importantes que foram implementadas para a população idosa. No final do século XX, ocorreu uma mobilização do Conselho Estadual do Idoso do Rio Grande do Sul, assim como universidades e prefeituras, com perspectivas de que os idosos fossem beneficiários na política pública de esporte e lazer (Blessmann, 2007). Dentre outras ações, foram criados os jogos adaptados para o idoso, nos quais o esporte que mais se destacou, por seu caráter voltado ao rendimento, foi o Câmbio. Este esporte é uma adaptação do voleibol com objetivo de reduzir a intensidade do exercício e oportunizar a participação até mesmo daqueles que não se consideram aptos para jogar.

Após a inserção dessas políticas, questiona-se sobre de que forma o esporte pode potencializar a promoção na saúde dos idosos participantes. Compreender esse contexto é importante para auxiliar profissionais que atuam com essas pessoas e organizações de eventos a melhor atenderem as necessidades para uma velhice com mais qualidade. Dentro desse contexto, realizamos este trabalho com o objetivo de compreender a prática do Câmbio vivenciada por idosos e suas possíveis relações com a saúde, no seu entendimento mais amplo.

\section{MÉTODO}

O referencial teórico-metodológico escolhido para o presente estudo foi a etnografia. Essa metodologia apresenta como instrumentos de investigação a observação participante e a entrevista (Velho, 1978; Rocha e Eckert, 2008). Neste tipo de investigação, o pesquisador se insere em um contexto para que ele possa vivenciar realidades diferentes, formas de sociabilidade e de valores distintas para que consiga compreendê-las.

Para a realização do presente estudo, investigamos grupos de idosos que praticavam o Câmbio, na cidade de Porto Alegre - RS. A modalidade câmbio consiste em uma adaptação do voleibol e ocorre nas mesmas dimensões da quadra do esporte já consolidado. $\mathrm{Na}$ maioria dos jogos e torneios os times são compostos por nove jogadores (possibilitando além destes, mais três reservas); é permitido somente 3 indivíduos do sexo masculino por time; há um rodízio onde todos os jogadores trocam de posição em quadra (semelhante ao voleibol); somente o jogador da posição central (posição 8) pode arremessar a bola; ao arremessar para 
a quadra adversária, não é permitido saltar, pular ou ultrapassar a linha dos três metros. Essas adaptações ficam bem claras em todos os torneios observados.

Em relação à idade dos participantes, no decorrer da pesquisa foram observadas duas categorias: máster (entre 50 e 59 anos) e Sênior (a partir dos 60 anos). Apesar disso, optamos em utilizar o termo idoso para referir aos praticantes de uma forma geral, visto que a maioria dos integrantes se encontra nesta faixa etária bem como o motivo da adaptação do esporte ser voltado para este público específico.

A pesquisa foi iniciada com dois grupos de jogadores de câmbio pertencentes aos parques públicos Ararigbóia e Ramiro Souto, situados em bairros distintos da cidade de Porto Alegre/RS. A pesquisa etnográfica ocorreu no período de $15 / 03 / 2013$ a 27/09/2013. Neste período de investigação, totalizamos vinte e três diários de campo, sendo nove no Parque Ararigbóia e nove no Parque Ramiro Souto, além de cinco competições. Cabe ressaltar que, os nomes dos sujeitos de pesquisa foram alterados para manter o anonimato e esse trabalho seguiu as reflexões éticas colocadas por Fonseca (2008), quando pauta as peculiaridades dos estudos etnográficos e suas negociações com os informantes

Durante as observações algumas questões foram sendo colocadas para que guiassem o olhar: Quem são esses idosos? Porque escolheram o câmbio? Por que o câmbio era vivenciado pautado pelos resultados? Como essa forma de viver o esporte se relacionava com as demandas de saúde daqueles idosos?

Realizamos também oito entrevistas semiestruturadas, as quais complementaram as informações obtidas pela observação participante. Em relação ao roteiro das entrevistas semiestruturadas, foram utilizadas as seguintes perguntas norteadoras: Qual o seu nome? Qual sua idade? Quais atividades físicas e esportivas você pratica? Com que frequência? Como o câmbio se insere nessa rotina? Há quanto tempo pratica câmbio? Onde começou? Por que tu jogas câmbio e não outra modalidade? Por que escolheu jogar pelo time que tu joga com as pessoas que tu joga? O que tu acha da forma como funciona a rotina do câmbio? O que poderia ser diferente? Por quê? Após uma partida o que deve ter acontecido para que você tenha considerado "hoje valeu a pena"? De que forma você acha que o câmbio interfere na sua saúde? Por quê? O que te leva a permanecer no câmbio? Que coisas te fazem voltar?

A partir desse processo de investigação obtemos informações que nos possibilita compreender a prática do Câmbio e algumas relações com a saúde dos idosos, no seu entendimento mais amplo, as quais apresentamos a seguir.

\section{RESULTADOS E DISCUSSÃO}

\section{Como os idosos vivenciam o esporte?}

A primeira visita no parque Ararigbóia ocorreu no dia $15 / 03 / 2013$. Os 'treinos' ocorriam nas sextas à tarde. O local dispõe de uma quadra poliesportiva coberta onde eram realizados os treinos de câmbio e os professores são funcionários da prefeitura. Segundo o planejamento da professora Ana a ideia era que houvesse uma turma de iniciantes às 14 horas e, para o pessoal que já está acostumado a jogar, o treino iniciasse às 15 horas. Entretanto, por falta de público de iniciantes, os treinos de fato começavam às $14 \mathrm{~h} 30 \mathrm{~min}$ e os idosos chegavam aos poucos, muitos perdendo o aquecimento e a primeira partida. Além disso, havia a frequência de 20 a 25 participantes por treino, mantendo-se basicamente os mesmos frequentadores. As idades dos participantes variavam entre 50 até por volta de 80 anos, sendo em sua maioria mulheres. Em relação às competições, a equipe somente ia com a categoria Sênior (acima de 60 anos) utilizando o nome de equipe 'Sem Limite'.

No parque Ramiro Souto, a primeira visita ocorreu no dia 19/04/2013. O que mais chamou a atenção foi o fato de as quadras serem em local aberto, diferentemente do outro local investigado. Os treinos ocorriam quartas e sextas pela manhã. A média de pessoas era um pouco maior comparado ao Ararigbóia, cerca de 30 participantes. Neste grupo, havia uma divisão bem definida de uma 'equipe competitiva' e dos 'iniciantes' que buscavam aprender. $\mathrm{O}$ primeiro grupo tinha seu horário definido às 9 horas da manhã e o segundo grupo, se integrava ao primeiro a partir das dez da manhã. Apesar de os horários e grupos estarem bem definidos e estabelecidos, eram poucos os integrantes que cumpriam o horário, pois a maioria 'chegava aos poucos', muitas vezes dificultando a ocorrência de uma boa partida. Nas competições, o grupo do Ramiro Souto apresentava equipe tanto para a categoria Sênior (acima de 60 anos) como para a categoria Máster (a partir dos 50 anos).

Embora nas competições as equipes dos dois parques se apresentassem de maneira separada, algumas situações que presenciamos faziam nos questionar se estávamos investigando dois grupos distintos ou apenas um grande grupo que frequentava locais diferentes. Começamos a observar que, quando íamos ao Parque Ramiro Souto pela manhã, encontrávamos os mesmos idosos de tarde no Parque Ararigbóia. Através de comentários dos participantes, soubemos que essa prática não era restrita a apenas estes locais, mas era comum no universo do câmbio da cidade de 
Porto Alegre. Além deste acontecimento frequente, o fato de ocorrer 'empréstimo' de jogadores entre as equipes, combinações para irem aos jogos juntos e, até mesmo, passar o tempo entre os intervalos de jogos nas competições conversando eram aspectos observados que corroboravam essa característica.

Desta maneira, podemos dizer que os dois grupos distintos que foram estudados, podem ser considerados um grupo amplo de pessoas que frequentava dois espaços públicos diferentes da cidade de Porto Alegre para praticar o câmbio. E este grande grupo se conhecia e possuía relações sociais tanto no âmbito esportivo como em atividades fora deste contexto. A forma como esse mesmo grupo de participantes vivenciava o esporte adaptado já foi debatida em pesquisa realizada anteriormente (Hauser et al., 2015). Contudo, para uma melhor compreensão do debate acerca de como o esporte pode ter relações com a saúde dos participantes, é importante relatar brevemente os três contextos em que o esporte ocorre nos grupos investigados.

No primeiro deles, podemos tratar como 'jogo sem critérios de divisão de times'. Esse tipo de jogo ocorria de maneira semelhante nos grupos investigados, sendo que sua característica principal era que não houvesse nenhum critério na hora de divisão dos times, ou seja, os integrantes iam chegando e se adequando aos outros encontrados em quadra. Nesses momentos, as características são mais relacionadas aos conceitos de "esporte-lazer", tendo uma menor preocupação com o resultado do jogo.

Em um segundo momento, no qual poderíamos dizer que os aspectos voltados para o esportelazer e esporte-rendimento estariam em equilíbrio, denominamos em nossos diários como o jogo 'com critério de divisão de times'. Este ocorre principalmente anteriormente às competições, com o objetivo de preparar os jogadores para o jogo competitivo. Dentre as atitudes comuns deste jogo, destaca-se o costume de escalar os jogadores de acordo com a qualidade técnica. Além disso, o placar já se mostra mais relevante e há dicas e até orientações de alguns integrantes para os outros companheiros. Segundo relato dos próprios participantes, esse tipo de jogo tem 'algo a mais'. Por exemplo: "após a divisão dos times os erros já não geram mais sorrisos. $O$ jogo parece mais tenso, há até um silencio no ginásio" (Diário de Campo - 03/05/2013).

Além destes, um terceiro momento se destaca por ter os aspectos de 'esporte-rendimento' em mais destaque. Estes seriam os jogos muitas vezes denominados 'de integração' de idosos, que são compostos de jogos amistosos ou torneios competitivos entre equipes de câmbio da região metropolitana de Porto Alegre e interior do estado do Rio Grande do Sul. Dentre as principais características, destacase a presença de placar, juiz e de fases eliminatórias. Além disso, o fato de haver um adversário 'de fora', um oponente, é um fator que pode fazer que os aspectos relacionados à competição se destaquem. Normalmente esses jogos ocorriam em outros ginásios da capital ou até mesmo em outras cidades do estado.

\section{A visão ampliada de saúde e suas interrela- ções com a prática do Câmbio}

A prática esportiva moderada apresenta tanto benefícios físicos quanto psicossociais para a saúde dos idosos (Wong et al., 2018). Entretanto, alguns aspectos em relação a saúde e esporte-rendimento costumam gerar polêmica e algumas controvérsias por parte de autores (Faria Junior; Santos, 2011; SBME, 2001). Apesar dos grupos investigados serem considerados de equipes amadoras e de esporte adaptado para idosos, nos momentos em que presenciamos aspectos voltados ao esporte rendimento mais presentes, pudemos perceber algumas situações nas quais a prática esportiva poderia ir ao desencontro da expectativa que se tem quando nos referimos à saúde física dos idosos participantes.

Em relação à saúde física, na premissa da perspectiva biológica, as pessoas de idade avançada ao praticarem atividades físicas com regularidade, quando comparadas as de vida ociosa, mostram melhor adaptação orgânica aos esforços físicos, além de maior resistência às doenças (Spirduso, 2005). Especificamente em relação ao câmbio, podemos considerar que essa modalidade auxilia na manutenção e desenvolvimento de diversas capacidades como a cardiorrespiratória, força, equilíbrio e agilidade as quais são fundamentais para a manutenção da independência e autonomia para idosos.

Segundo o posicionamento oficial da Sociedade Brasileira de Medicina do Esporte (2001) sobre esporte competitivo para pessoas acima de 35 anos, o exercício não precisa ter caráter competitivo para proporcionar benefícios de saúde. Entretanto, serve de estímulo para realizá-los com intensidade mais alta, com maiores ganhos em termos de saúde e também podendo auxiliar a assegurar uma maior regularidade na prática. Além dos benefícios da própria prática de câmbio, nos grupos investigados, era comum durante o período de investigação ouvir relatos de idosos estarem no treino buscando melhorarem suas habilidades para a competição posterior.

Além disso, na busca de minimizar possíveis lesões que possam ocorrer em decorrência do esporte, 
muitos dos idosos investigados realizam uma atividade física complementar aos vários treinos de câmbio na semana. Por exemplo a participante Anita, que na ida para o evento de Dois Irmãos (Diário de Campo $04 / 05 / 2013$ ) relata fazer outras atividades, pois sabe do risco de lesão e que tem que preparar o corpo para jogar. Deste modo, além de passarem vários dias da semana se movimentando e obtendo benefícios através do esporte adaptado, os aspectos relacionados ao esporte-rendimento podem proporcionar um estímulo para que haja a inserção de outros tipos de atividade física.

Além das implicações físicas para a saúde dos idosos investigados, os dados etnográficos nos provocaram a olhar com maior atenção que a adaptação do esporte estudado também tem o objetivo reinserir o idoso na sociedade, visando maior interação com os outros, melhorando o estado psicológico e social do indivíduo. Aparentemente, nos grupos investigados, o esporte apresenta uma conotação positiva frente às variáveis psicológicas e sociais do idoso. É quase que consenso dentro dos grupos investigados que, o fato de estar fora de casa, inserido na sociedade, possui relevância para a saúde dos indivíduos. Giovana quando perguntada sobre a influência do câmbio na sua saúde, responde: "Tu não precisa ir no psicólogo, terapeuta. Isso já faz uma terapia só pela sociabilidade que dá né" (GIOVANA, Entrevista - 27/09/2013).

Sob o mesmo ponto de vista, para os integrantes que participam das competições, os valores voltados ao esporte-rendimento também podem ser importantes frente aos aspectos psicológicos e sociais no envelhecimento de cada um. Primeiramente, podemos citar que o estímulo à prática esportiva pode ser visto de maneira benéfica para os participantes. Segundo Deps (2009), atividades grupais são importantes por estarem associadas a baixos níveis de estresse e depressão. Ficou evidente ao longo do trabalho de campo que momentos como a integração do grupo em viagens para jogos, como brincadeiras no ônibus, almoços em outras cidades e sociabilidade com participantes de outras regiões do estado do Rio Grande do Sul, não seriam possíveis caso não houvesse o estimulo da competição.

Ademais, outros aspectos relacionados ao esporterendimento também podem ser relevantes para a saúde do participante. $O$ fato de haver medalhas, troféus e chaveamento, provoca esse estímulo maior à competição e à simples prática da modalidade. Esses elementos possuem valores simbólicos para os participantes. Mesmo não obtendo os prêmios, o fato é que para Deps (2009), há importância de haver um significado para a existência, visto que "garantir anos à vida, sem garantir à mesma algum significado, não é a melhor resposta para o desafio do envelhecimento" (Deps, 2009. p. 58). Dessa forma, para os idosos que competem e participam dos eventos, os aspectos relacionados ao esporte-rendimento teriam uma conotação positiva frente à melhora do bem-estar psicológico e social, atribuindo à suas vidas, um novo significado.

Em contrapartida, o esporte-rendimento em indivíduos idosos pode trazer uma série de problemas possíveis. Faria Junior e Santos (2011) não julgam recomendáveis as atividades competitivas para a maioria das pessoas idosas, ainda que consideradas adaptadas. Estes mesmos autores destacam que:

Situações competitivas aumentam o potencial de risco pessoal inerente à própria atividade física, que não deve ser negligenciado, e que, em se tratando de idosos, estes riscos se apresentam exponenciados, dadas às características que marcam esta fase da vida (Faria Junior; Santos, 2011, p. 100).

Essas falas dos autores remetem a pensar que o esporte-rendimento nesta faixa etária seria algo a ser abolido. A partir das nossas observações esse entendimento deve ser, ao menos, colocado em suspensão, já que o envolvimento com o esporte e a busca pelo rendimento de performance era uma maneira significativa dos nossos informantes vivenciarem a velhice. Entretanto, atentos a essa explanação dos autores, trazemos algumas reflexões nas quais o esporte-rendimento atua em uma perspectiva de risco frente ao processo do envelhecimento.

$\mathrm{Na}$ primeira delas, em alguns momentos determinados, idosos descumprem ordens médicas devido a certos problemas de saúde. Como exemplo, observamos Francisco nos intervalos dos jogos realizados no SESC (Diário de Campo 23/05/2013) passando spray na panturrilha e região da coluna lombar. Além disso, ele relata-me estar jogando 'dopado' a base de remédios por causa da dor e quando perguntamos se está liberado pelo médico ele diz que não. Bento, por sua vez, mesmo estando com uma lesão importante no ombro, não podendo levantar o braço acima do ângulo de $90^{\circ}$, estava presente em quadra jogando (Diário de Campo 29/08/2013). Essas observações são semelhantes ao que Stigger (2002) encontrou em sua tese, quando indivíduos com problemas cardíacos ou com dores constantes, continuavam a jogar nos grupos investigados.

Além disso, participantes idosos de outras pesquisas envolvendo práticas esportivas indicaram a percepção de que o esporte pode aumentar o risco de lesões e que é mais difícil de se recuperar delas com o avançar 
da idade (Jenking et al., 2017), sugerindo, dessa forma, possíveis aspectos negativos do esporte competitivo. Outro exemplo de que os aspectos voltados ao esporte-rendimento podem se contrapor à saúde dos idosos em nossas observações é o caso de Aparecida, que teve de se afastar das quadras durante um ano após uma queda em uma competição. Após esse ocorrido, ela comenta que não quer mais competir e estava no evento só por que estava faltando gente. Ela diz: "agora só quero brincar, me divertir" (Diário de Campo 23/05/2013).

Além deste caso, outras falas nos mostram essa relação de que nas competições a saúde ficaria em 'segundo plano'. Na primeira delas, Tereza, quando questionada sobre a relação do câmbio na sua saúde, comenta: "Quando o saque é muito forte, nos treinos, a gente tem que se cuidar, ou não pega... pra não se machucar... os dedos" (TEREZA, Entrevista 27/09/2013) dando a entender que em competições, provavelmente ela iria na bola deixando de 'se cuidar'. Essa constatação de que nos treinos a atividade seria menos perigosa para a saúde é encontrada também nas falas de João: "Nos treinos elas interferem de uma maneira benéfica" (JOÃO, Entrevista - 27/09/2013).

A partir destas falas, nos comentários dos três sujeitos, podemos perceber uma conotação de que, nos treinos, onde os aspectos relacionados ao esporterendimento não ficam tão em evidência, os riscos de prejuízo à saúde seriam menores em relação às competições. Além disso, no caso de Aparecida ela nos remete a pensar que o "brincar e se divertir" só seria possível durante os treinos, longe das competições. Dessa forma, através das observações e entrevistas, verificamos que os aspectos relacionados ao esporterendimento podem contribuir para 0 bem-estar físico dos indivíduos. Entretanto, em alguns casos a competição pode estimular o idoso a ultrapassar os seus limites, gerando alguns problemas físicos e agravando lesões.

Com o direcionamento do esporte para uma conotação mais competitiva, nos questionamos em relação ao bem-estar psicológico e social dos participantes, tanto aos que vão às competições devido ao alto nível de stress bem como o que, de certa forma, fica sem vaga no time que compete devido ao seu baixo nível de habilidade técnica.

Partindo do objetivo inicial da adaptação do esporte (do voleibol para o Câmbio) o qual seria "reduzir a intensidade e oportunizar a participação até mesmo daqueles que não se consideram aptos a jogar" (Blessmann, 2007, p.148), algumas questões nos inquietaram no decorrer da investigação. De certa forma, quando tratamos de jogos no decorrer dos treinos, independente se há divisão pré-estabelecida de times ou não, ocorre sempre a inclusão dos participantes independente de suas limitações. Entretanto, para as partidas de campeonatos onde os aspectos de esporte-rendimento ficam em maior evidência, o nível técnico e uma afinidade maior com os líderes de cada equipe, ao que parece, se tornam os critérios para a escolha dos jogadores.

Para contextualizar essa temática, Azevedo e Filho (2011) afirmam que a competição inerente aos esportes de rendimento não trabalharia em favor dos propósitos generosos da inclusão e da igualdade. Um exemplo para contextualizar foi o ocorrido no dia 19/06/2013, quando em um treino com poucos integrantes emerge entre os participantes o assunto de uma competição que seria realizada na cidade de Erechim/RS. Após Débora sair do treino cedo, Vera diz que não irá por não ter sido convidada, o que é motivo de comentário de Violeta: "é, se não teve competência para ir" (Diário de Campo 19/06/2013). Esse fato demonstra que 'ser competente' é um aspecto importante para a 'escolha' de quem irá jogar nos campeonatos.

Além disso, contextualizamos com o que foi observado no torneio amistoso de Dois irmãos/RS onde após uma derrota do time 'Sem Limite' devido a vários erros de Amélia, ouvimos o seguinte relato da jogadora Giovana: "ela não pode competir, ela fica nervosa, só ela entregou seis pontos" (Diário de Campo, 23/05/2013). No outro jogo da mesma competição foi possível perceber que enquanto a equipe 'Sem Limite' vencia facilmente, Amélia ficou isolada do lado de fora da quadra assistindo a partida. Além disso, após este acontecimento observamos poucas vezes a presença dela nos treinos no Ararigbóia e em competições. Por fim, a relevância do rendimento também fica em evidência na entrevista realizada com João, quando perguntando o que um companheiro precisa ter para entrar e se manter no time:

Depois que começou a jogar isso aí, começou a assumir característica de disputa né. Então se espera alguém que já tenha noção pra acompanhar o nosso ritmo, que tenha alguma habilidade, que tenha dedicação, que se esforce e que siga as normas do grupo e, isso aí, esse tipo de convívio é que vai gerar um grupo mais fechado (JOÃO, Entrevista - 27/09/2013).

$\mathrm{Na}$ resposta acima, podemos perceber que o participante faz uma relação direta entre o fato de o esporte ter uma característica de disputa, e associa com o rendimento do companheiro. De certa forma, o que é encontrado no câmbio também foi encontrado no trabalho de Silveira (2008) onde comenta em sua etnografia que, no grupo de futsal feminino investigado, o rendimento esportivo é um 
fato que exclui algumas praticantes do time. Além disso, estudo realizado com idosos da Austrália aponta que a "ausência de habilidade" é uma barreira para a participação no esporte (Jenking et al., 2017).

Desta forma, percebemos que os aspectos relacionados ao esporte-rendimento, como a busca pelo resultado, não estariam contribuindo para a inserção ou manutenção dos indivíduos em seus grupos. Dessa maneira, estaria contra a lógica do bemestar psicológico e social daquele indivíduo, o excluindo de atividades grupais com pessoas da própria geração que, segundo Deps (2009) favorecem o bem-estar, pois facilita a emergência de significados comuns e a maior aproximação interpessoal, permitindo a libertação de sentimentos guardados. Outro benefício do esporte coletivo em idosos seria o sentimento de pertencimento, o qual já foi verificado em pesquisas envolvendo grupos de idosos (Zabaleta, 2012; Jenking et al., 2017), que também poderia ser 'perdido' por aqueles que não conseguem se manter competitivos.

Além da perspectiva relacionada à inclusão, em entrevista com Vera, líder do grupo Ramiro Souto, sobre como o câmbio poderia interferir em sua saúde:

Olha, as competições na minha saúde às vezes ela me prejudica. Tem dias quando eu volto das competições eu volto assim "moída", estressada porque na verdade além de jogar eu vou como coordenadora do grupo. Aí sobrecarrega. Eu tenho que jogar, tenho que cuidar de todo o resto. Isso aí me estressa muito. Eu chego em casa tenho que tomar um relaxante, tenho que descansar porque tô bem 'moída' mesmo. (VERA, Entrevista - 27/09/2013)

Com isso, poderíamos observar que além de possíveis exclusões de participantes, os aspectos relacionados ao rendimento esportivo podem ter uma conotação de desgaste e cansaço psicológico frente a esta participante. Nesse caso particular, ela é a líder do grupo e, além de jogar, tem mais afazeres do que os demais, aspecto que 'agrava' a sua situação.

\section{CONSIDERAÇÕES FINAIS}

No presente estudo, pudemos observar que a prática do câmbio por parte dos idosos participantes dos grupos investigados nos faz refletir sobre as relações dessa prática esportiva na saúde dos praticantes. Em um mesmo momento, a prática esportiva pode acarretar em benefícios para uma dimensão relacionada à saúde enquanto que pode atenuar 'riscos' em outros aspectos relacionados à saúde. Cabe ressaltar que nos momentos em que os aspectos voltados para o esporte-lazer estavam mais presentes, os 'riscos' para a saúde foram menos observados. Contudo, nos momentos em que o esporte apresentava características mais voltadas para o rendimento, apesar dos 'riscos' aumentados para a saúde o esporte-rendimento traz consigo determinados aspectos positivos que também devem ser ponderados.

Assim, no que se trata de saúde, esporte e envelhecimento devemos destacar que a saúde deve ser refletida sob uma visão ampliada, levando em consideração aspectos físicos, psicológicos e sociais. Além disso, o esporte pode ser vivenciado de diversas formas, podendo ter significados distintos atribuídos por um mesmo grupo de participantes. Ademais, os benefícios da prática também podem ser diferentes entre indivíduos de um mesmo grupo. Espera-se que esse debate possa auxiliar professores de educação física e organizadores de eventos de câmbio a refletirem a respeito de suas práticas, levando em consideração as formas de vivenciar o esporte e suas interrelações com a saúde

\section{CONFLITO DE INTERESSE}

Os autores declaram não haver conflito de interesse

\section{REFERÊNCIAS}

Azevedo MAO, Filho AG. Competitividade e inclusão social por meio do esporte. Rev Bras de Ciênc esporte. 2011; 33(3):589-603.

Blessmann EJ. A sociabilidade e a ludicidade nos jogos esportivos adaptados para idosos. In: Stigger MP, González FJ, Silveira R. (orgs). O esporte na cidade. Estudos etnográficos sobre sociabilidades esportivas em espaços urbanos. Porto Alegre: Editora UFRGS. 2007.

Deponti RN, Acosta MAF. Compreensão dos idosos sobre os fatores que influenciam no envelhecimento saudável. Estud. Interdiscip envelhec. 2010; 15(1): 33-52.

Deps VL Atividade e bem-estar psicológico na maturidade. In: NERI AL (org.) Qualidade de vida e idade madura. 8 ed, Campinas: Papirus, 2009.

Elias N, Dunning E. O lazer no espectro do tempo livre. In: Elias N, Dunning E. A busca da excitação. Lisboa: Difusão Editorial, Lda, 1992.

Famose JP. Rendimento Motor: um intento de definición. In (Dir.) Cognición y rendimiento motor. Barcelona: Inde, $\overline{1999 .}$

Faria Junior AG. Santos ALA. Educação Gerontológica e Desportos Olímpicos para Idosos.. Niterói: IEG, 2011.

FONSECA, C. O anonimato e o texto antropológico: dilemas éticos e políticos da etnografia 'em casa'. Teoria e Cultura. 2008; 2(1): 39-53.

Hauser E, Silveira R, Stigger, MP. Câmbio: Um Estudo Etnográfico Sobre a Prática Esportiva Adaptada para Idosos, Pautada pela Competição. Licere. 2015; 18(4): 49-70.

IBGE. Instituto Brasileiro de Geografia e Estatística. Primeiros resultados definitivos do Censo 2010: população do Brasil é de 190.755.799 pessoas. Disponível em: http://www.ibge.gov.br/home/ presidencia/ noticia_visualiza.php?id_noticia=1866\&id_pagina=1 - [Acesso em: 20/06/2013].

Jenking CR. et al. Sport for Adults Aged 50+ Years: Participation Benefits and Barriers. J Aging Phys Act. 2017; 1-31. doi: 10.1123/japa.2017-0092. 
Labra C, Guimaraes-Pinheiro C, Maseda A, et al. Effects of physical exercise interventions in frail older adults: a systematic review of randomized controlled trials. BMC geriatrics. 2015;15(1):154. DOI: doi: 10.1186/s12877-015-0155-4.

Pacheco AC, Stigger, MP.. "É lazer, tudo bem, mas é sério": notas sobre lazer a partir do cotidiano de uma equipe máster feminina de voleibol. Movimento. 2016; 22(1):129-142.

Rocha ALC, Eckert C. Etnografia: saberes e práticas. In: Pinto, CRJ, G, Cuazzelli.B (orgs.). Ciências humanas: pesquisa e método. Porto Alegre: Editora da UFRGS, 2008.

Silveira R. Esporte, homossexualidade e amizade. Estudo etnográfico sobre o associativismo no futsal feminino 2008. 156 f. Dissertação (mestrado) Curso de educação física, departamento de educação física, UFRGS Porto Alegre. 2008

SBME. Sociedade Brasileira de Medicina do Esporte. Esporte competitivo em indivíduos acima de 35 anos. Rev Bras Med Esporte. 2001, 7(3):83-92.

Spirduso WW. Dimensões físicas do envelhecimento. $2^{2}$ ed. São Paulo: Manole; 2005.

Stigger MP. Esporte, lazer e estilos de vida: um estudo etnográfico. Editora autores associados. 2002.
Stigger MP. Educação Física, Esporte e Diversidade. Autores Associados. Campinas, 2005.

Velho G. Estranhando o familiar. In: NUNES EO. (org). A Aventura sociológica: objetividade, paixão, improviso e método na pesquisa social. Rio de Janeiro: Zaha, 1978.

Warburton DE, Bredin SS. (2016). Reflections on physical activity and health: what should we recommend?. Can J Cardiol, 2016; 32(4):495-504.

WHO. World Health Organization. The Declaration of Alma Ata. Presented at. In: International Conference on Primary Health Care. Alma Ata. 1978.

WHO. Global recommendations on physical activity for health. World Health Organization, 2010.

WHO. World report on ageing and health. World Health Organization, 2015.

Wong JD, Son JS. West ST et al. A Life Course Examination of Women's Team Sport Participation in Late Adulthood. Journal of aging and physical activity. 2018; 1-34. DOI: https://doi. org/10.1123/japa.2017-0193

Zabaleta ASD. Velhice e Lazer. Um olhar etnográfico para um projeto de idosos. 2012. 103 f. Dissertação (mestrado) Curso de educação física, departamento de educação física, UFRGS. Porto Alegre. 2012 